\title{
IKEA and Wal-Mart: Comparison of Transferable Factory Specific Advantages (FSAs) in Internationalization
}

\section{Hussein Salloum}

Dynergy Technologies

\section{Introduction}

This study investigates the cases of two mega size retailers, IKEA and Wal-Mart and their internationalization approaches. Whereas IKEA is a Sweden based company that started in 1934 and expanded to 52 countries by 2021 with 378 stores, Wal-Mart is US based company started in 1962 and expanded throughout 26 countries by 2021 with 11,443 stores.

\section{IKEA}

IKEA core business is focused on low -cost furniture. However, quality concerns were raised for such low, which has led IKEA to overcome this problem through making showroom where consumers would see their products and compare quality wise to others. In addition, IKEA has developed advantages to achieve its lowprice core competency throughout its development of in-house furniture design, flat packaging, low cost international suppliers, and low cost material and design. Above that, IKEA has few more advantages like mobilizing staff intuition and learning, diversification, and designing for children. IKEA started its expansion in 1963 and there have been several occasions where IKEA developed major strengths during the course of expansion which we will analyze in course of report.

\section{Wal-Mart}

Wal-Mart core retail business revolves on its "every day low price" (EDLP) and exceptional service. The low price was based on highly effective system of distribution, low supplier prices and creative technology. In 1991, Wal-Mart started its international expansion around the world and had very successful implementation of its core strengths, however faced major difficulties in Germany which will be our focus of analysis.

\section{Framework and Theory}

In this research, we will follow the theory of internationally transferrable and non transferrable factory specific advantages where we list the core competencies of every firm and the location advantage of each of these FSAs. Please refer Figure 1.1 for the diagram of FSAs 


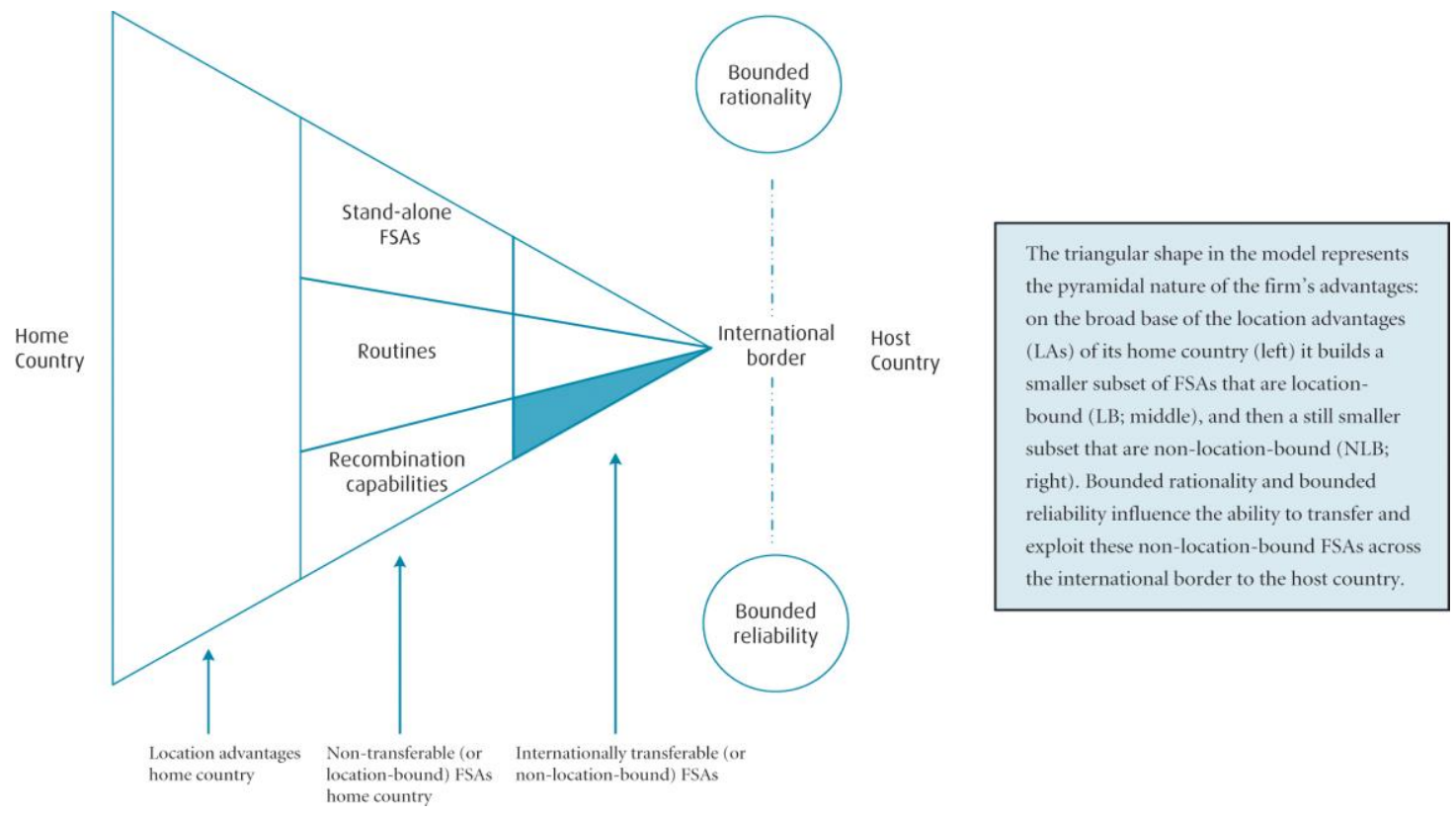

In addition, we analyze the type of archetype with the specific routine of IKEA and Wal-Mart. Normally, there are four general types listed as below:

\section{Centralized Exporter}

2. International Projector

3. International Coordinator

4. Multi-centered MNE

Further to above, we investigate the transferrable FSAs and non transferrable FSAs and the difficulties each of IKEA and Wal-Mart faced during their internationalization process.

\section{IKEA}

IKEA was successful to have core competency by developing "firm routines and recombination capabilities to produce core products which are put together to create end products". This was reflected in creating in-house design, flat packaging concept and having a wide network of low cost suppliers. These were distinctive from many other competitors and were unable to be easily imitated.

In this regard, IKEA spread out internationally with an approach of international projector using the same products and operational methods. The major FSAs were developed during its existence in home country where it faced several challenged like the quality issue which led to IKEA developing its showrooms. Later on in 1950s and 1960s, IKEA faced major boycott from Sweden suppliers and it started sourcing from Poland. Four decades ahead, IKEA established an international network of low-cost suppliers mainly coming from China and 
Poland. In house design and flat packaging were another transferrable FSA which were initially developed in home country and later on transferred throughout the host countries.

However, IKEA faced several challenges that affected the transferability of its FSA. These challenges were maintaining low prices with increasing administrative costs, in addition to running a extremely wide international operations. This was having direct impact on IKEA core strength which is low cost products as it has pressurized its profits and prices. IKEA was able to overcome this problem through giving more control to America IKEA CEO, requesting regions to meet cost to turnover ratio, and creating internal competition by making separations and franchising. IKEA still faced pressure on maintaining low prices in some countries like Poland.

Another FSA faced major challenge in China which is the flat packaging which would require assembly services. Due to nondesirablility of customers to assemble themselves, availability of low cost labour, and lack of cars with many consumers, this FSA was not successful.

Above that, IKEA FSA of having low cost suppliers throughout the globe have faced major restriction in India, where regulations forces IKEA to buy at least $30 \%$ of its material from Indian suppliers.

We can see that IKEA has followed Pattern III in its international expansion where FSAs are developed at home , and location bound knowledge are added in the host country to exploit its benefits.

\section{CAGE Analysis}

Ghemawat terms include four components which are organized into four categories: Cultural, administrative, geographic, and economic distance.

In China, IKEA has economic distance where there were differences in infrastructure characteristics, human resources, and income levels. However, India, IKEA faced mainly administrative distances due to the specific regulation of $30 \%$ minimum local sourcing for products.

\section{Wal-Mart}

Wal-Mart have developed its core competency on low pricing and exceptional service. In the home country, Wal-Mart developed its low prices from suppliers, efficient logistics, smiling to customers, meeting their expectations, huge operations, and offering products likable to American consumers. In addition, American market was rapidly growing market which allowed for fast growth of Wal-Mart operations in the US.

Wal-Mart followed the strategy of mid way between international projector and international coordinator. It has expanded in China, UK, Argentina, Brazil and Canada by implementing their home country model yet considered local conditions to adapt. 
Wal-Mart faced all kind of cultural, administrative, geographic, and economic distances in its entrance to German Market.

In the cultural distances, German consumers focus major part of their budgets on non retail products, and have minimum expenditures on retail products. In addition, German consumer considered smiling to customers as flirting, which Wal-Mart cancelled the practice accordingly. German consumers have their self service bagging attitude and require no assistance for labour to handle grocery bagging. Moreover, Wal-Mart German executives are not familiar with moving from one city to another which led to many resigning.

Regarding the administrative distances, Wal-Mart faced strict regulations such as zoning laws, store hours, fair trading and antitrust laws. These regulations have affected its core competency of offering low prices. above that, Germany has a strong worker unions and co-determination system which Wal-Mart is not familiar with. In fact, Wal-Mart was not able to implement its loss-leader strategy and faced legal issues to raise its prices.

With respect to geographic distances, Wal-Mart was obliged to close one of two factories due to its far location from its main stores.

Economic distances played major role in Wal-Mart expansion towards Germany. Due to the fact that German market was already saturated, its small size operations made it difficult for Wal-Mart to reduce prices. This was caused from reducing power of negotiations with suppliers.

\section{Comparison of IKEA and Wal-Mart}

Despite the difference in sizes and age of IKEA and Wal-Mart, we can compare companies core competencies, transferable FSAs, their home advantages, and difficulties they faced and way the overcome. Both companies started as retailers in their home countries where they have developed their competitive advantages for decades before they start their international expansion.

In their core competitiveness, both companies have focused on low prices products. to achieve this strategy, IKEA and Wal-Mart have developed several transferrable FSAs like low cost suppliers, effective operations, and interactive management process. However, both have followed initially the international projector strategy and tried to replicate their models in the host countries. Whereas IKEA had more transferrable FSAs and faced less resistance, mainly economic and administrative, Wal-Mart faced wider and deeper resistance that included all types of distances especially in Germany.

On the other hand, Wal-Mart has shown more flexibility than IKEA to adapt its operations and model in the host country to enhance its market penetration. In fact, Wal-Mart has approached the India market through joint 
venture with Bharti Enterprises and localized its products on shelves by $90 \%$. On the other hand, IKEA was late to localize its operations in India. in 2013, IKEA signed an agreement with the Indian states of Karnataka and Telangana to open its own stores.

\section{Conclusion}

IKEA concept of selling high quality products at low price through a pinpoint strategy has benefitted IKEA in its international expansion. Central control and product standardization are essential to the long term strategy of the firm. IKEA has enhanced its expansion through subsidiaries and franchises, yet local pressure will ultimately make IKEA change its strategy in order to become more sensitive to host countries demands. Joint ventures and strategic alliances are main factors towards building on its strategy. A modified organizational structure would allow the required infrastructure to support such ambition towards more successful internationalization. Whereas, IKEA has built its international expansion in Europe and America through company-owned subsidiaries, franchising was extensive in other areas of the world.

It is no doubt that Asian markets have potential when Wal-Mart launched its international expansion in 1990s. But Asian market is geographically distant, culturally different and logistically away from the US market. It would take huge resources, financially and resource-wise, to establish a presence in Asia.

\section{References}

[1] Verbeke, 2013 International Business Strategy (2 $2^{\text {nd }}$ ed), Cambridge

[2] http://www.ibtimes.com/ikea-signs-agreements-2-indian-states-open-stores-country-1694748

[3] http://www.executiveforums.com/resource.php?rID=65\&rType=A

[4] Core Competence- Based Differentiation Strategy: Creating Competitive Advantage, Journal of Global Strategic Management June 2008

[5] https://pmbarobinson.wordpress.com/2013/02/16/ikeas-core-advantages/

[6] http://www.strategy-business.com/article/13866?pg=all 